\title{
Transvenous Lead Extraction
}

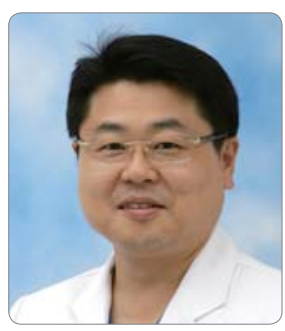

Boyoung Joung, MD, PhD

Division of Cardiology, Yonsei University College of Medicine, Seoul, Republic of Korea

Received: September 25, 2017

Accepted: September 29, 2017

Correspondence: Boyoung Joung, MD, PhD

Professor of Medicine, Yonsei Cardiovascular

Hospital, Yonsei University College of Medicine

50 Yonseino, Seodaemun-gu, Seoul, 03722

Republic of Korea

Tel: +82-2-2228-8460 Fax: +82-2-2227-7732

E-mail: cby6908@yuhs.ac

Copyright (C) 2017 The Official Journal of Korean Heart Rhythm Society Editorial Board and EUM \& Communications

\begin{abstract}
Cardiac rhythm management devices (pacemakers) are being increasingly implanted worldwide for the management of not only bradycardia but also arrhythmia and heart failure. This increase in the frequency of device therapy is paralleled with an increase in the requirement for systemic extraction. Safe lead extraction is central to the management of several complications related to pacemakers. The most common indication for lead extraction is systemic infection. Adhesions in chronically implanted leads can become major obstacles to safe lead extraction, leading to life-threatening bleeding and cardiac perforations. Currently, several extraction tools enable safe and successful transvenous lead extraction (TLE) of pacemaker and implantable cardioverter-defibrillator leads. This article provides a comprehensive review of the indications, tools, techniques, and outcomes for TLE. Operator experience is vital in determining success, as familiarity with a wide array of techniques will increase the likelihood of uncomplicated extraction. Lead extraction should, therefore, ideally be performed in high-volume centers with experienced staff and on-site support from a cardiothoracic surgical team that is able to deal with bleeding complications from cardiovascular perforation.
\end{abstract}

Key Words: - Pacemaker - Lead - Extraction

\section{Introduction}

The implantation rate of devices such as pacemakers (PMs) and implantable cardioverter-defibrillators (ICDs), with or without cardiac resynchronization therapy (CRT) options, has significantly increased over the last few decades, ${ }^{1-3}$ leading to a rising number of failed leads, device-related infections, and lead or device recalls. Consequently, the need for PM and/or ICD lead extractions is increasing. ${ }^{4}$

Recently introduced PM leads can typically be removed by direct traction. However, chronically implanted leads become encapsulated by fibrotic attachments..$^{5-8}$ Adhesions not only occur 
at the lead tip but also are commonly found along any length of lead where a contact between the lead and vein, valve, or endocardial structures such as the superior vena cava exists. ${ }^{5-10}$ Over the last 20 years, specific tools and techniques for transvenous lead extraction have been developed to assist in freeing the lead body from the adhesions as well as the lead tip from the myocardium, to prevent laceration of the myocardium and to provide enough room for the lead to be withdrawn while preventing its disintegration. Specialized tools include locking stylets, telescoping sheaths with or without additional cutting capability (e.g., metal composition, excimer laser, and radiofrequency current), snares, grasping devices, or other devices used to engage or entrap and remove lead fragments. The current review aims to provide an overview of lead extraction, including the success and complication rates of different extraction methods currently available.

\section{Definition of lead and system extraction}

Within the general category of "lead removal," distinctions must be made between simple procedures that can be performed via the implant vein without specialized tools ("lead explant") and removal of leads involving more complex procedures ("lead extraction"). ${ }^{11}$ The definitions are as follows:

Lead removal: Removal of a pacing or defibrillator lead using any technique

Lead explant: Lead removal using simple traction techniques (no locking stylet, telescoping sheaths, or femoral extraction tools)

Lead extraction: Removal of a lead that has been implanted for more than 1 year, removal of a lead, regardless of the duration of implant, that requires the assistance of specialized equipment that is not included as part of the typical implant package, and/or removal of a lead through a route other than via the implant vein

ICD leads may require specialized extraction equipment even when the duration of implantation is less than 1 year.

\section{Indications for lead extraction}

The most common indication for extraction is PM infection, including pocket infection or endocarditic vegetation involving any intravascular component of the PM system. However, other important common indications include lead malfunction (fracture or failure), lead or device erosion, lead upgrade, retained lead or lead fragment causing potentially life-threatening arrhythmias, thromboembolic complications or venous obstruction, device recall, and a lead that interferes with the operation of another implanted device (e.g., PM or ICD). Recently published guidelines can be found in the Heart Rhythm Society Expert Consensus on Lead extraction (Table 1). ${ }^{11}$

\section{Tools, technique and outcomes for lead removal}

Most lead extractions are achieved through a percutaneous transvenous approach. However, the following are the three main indications for open surgical extraction: failed percutaneous lead extraction, surgical unrelated cardiac disease (such as pre-existing need for valve replacement), and endocarditis with very large infected vegetations that would require open extraction to minimize embolic complications. The clinical outcomes of different extraction methods are presented in Figure 1. ${ }^{12}$

\section{Simple traction}

The first attempt to extract a transvenous PM or ICD lead usually involves simple traction. Simple traction has been performed for almost 40 years and is the most basic technique for lead removal. It can be combined with graded traction and/or rotational forces. This technique of applying traction to the lead in combination with the use of tools typically supplied for lead implantation (non-locking stylets, fixation screw retraction clips) is particularly successful in leads with recently implanted leads. ${ }^{13}$ The success rate of TLE by simple traction was observed in 9-31\% (median, 19\%) of patients and in 7-85\% (median, 28\%) of leads. The success rates of simple traction vary considerably among different studies.12 No simple traction-related deaths were reported in the 3,769 patients in whom it was performed.

The main limitation of manual traction is its limited success in completely removing older leads. The forceful traction may sever the insulation and conductor coils of the leads, resulting in denuded retained lead fragments. Major complications, including three cases of cardiac avulsion requiring surgical intervention, occurred in $0-1.3 \%$ of patients (Figure 1 )..$^{12}$ 
Table 1. Indications for lead extraction

\section{Class I}

1. Sepsis (including endocarditis) as a result of documented infection of any intravascular part of the pacing system or of a pacemaker pocket infection when the intravascular portion of the lead system cannot be aseptically separated from the pocket.

2. Life-threatening arrhythmias secondary to a retained lead fragment.

3. Retained lead, lead fragment, or extraction hardware that poses an immediate or imminent physical threat to the patient.

4. Clinically significant thromboembolic event caused by a retained lead or lead fragment.

5. Obliteration of occlusion of all useable veins, with the need to implant a new transvenous pacing system.

6. Lead interferes with the operation of another implanted device (e.g., pacemaker or defibrillator).

Class II

1. Localized pocket infection, erosion, or chronic draining sinus that does not involve the transvenous portion of the lead system, when the lead can be cut through a clear incision that is totally separate from the infected area.

2. Occult infection for which no source can be found and for which the pacing system is suspected.

3. Chronic pain at the pocket or lead insertion site that causes significant discomfort for the patient, is not manageable by medical or surgical technique without lead removal, and for which no acceptable alternative is available.

4. Lead that, due to its design or its failure, may pose a threat to the patient, although the threat is not immediate or imminent if the lead is left in place.

5. Lead that interferes with treatment of a malignancy.

6. Traumatic injury to the entry site of the lead for which the lead may interfere with reconstruction of the site.

7. Leads preventing access to the venous circulation for newly required implantable devices.

8. Nonfunctional leads in a young patient.

\section{Non-powered traction tools}

Over time, leads become adherent to either the myocardium or vascular walls in varying degrees owing to encapsulating fibrotic tissue at the contact sites. Thus, during application of traction to chronically implanted leads, force is distributed over all fibrotic binding sites and weakened at the distal end of the lead. Non-powered tools are developed to direct the force of traction to the length or at the distal end of the lead (locking stylets) or to disrupt and dilate the encapsulating fibrotic tissue (mechanical dilator sheaths).

\section{Locking stylets}

This technique uses a special traction device to minimize lead disintegration. A locking stylet is introduced into the central lumen of the lead where it can be locked into the coil close to the

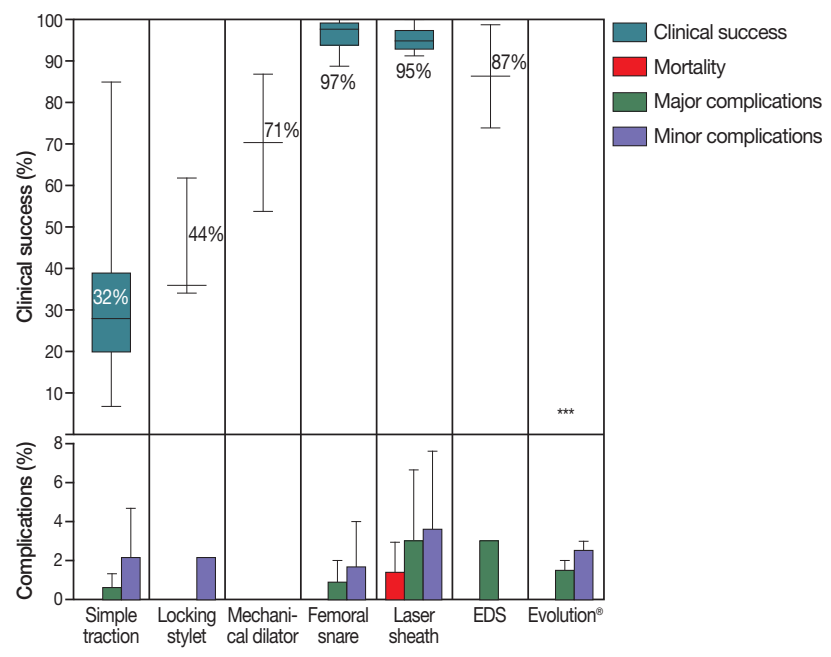

Figure 1. Clinical outcomes of different extraction methods. Clinical success rate is reported per lead and complication rate is reported per patient. The percentages represent the mean success rate.

"Clinical success or complication rates were not reported for this extraction method.

EDS, Electrosurgical dissection sheath 

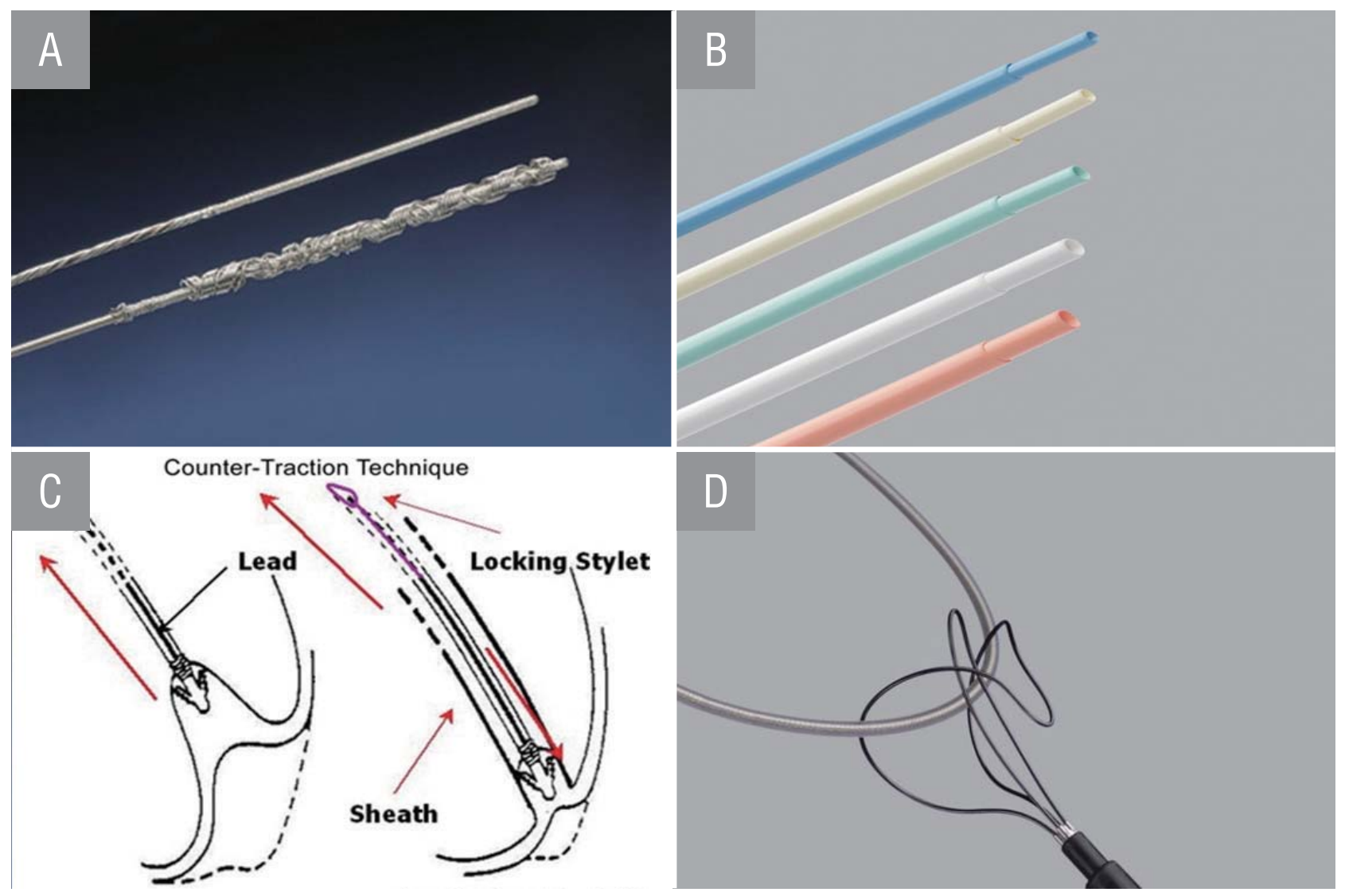

Figure 2. A, Liberator ${ }^{\circledast}$ locking stylet. B, Byrd dilator sheaths telescoping polypropylene. C, Counter-traction technique. D, Needle's eye snare.

lead tip or anywhere along the conductor coil (Figure 2A). The improved traction helps prevent elongation of the lead body and coil during exertion. The TLE success rate after the use of both simple traction and locking stylets was observed in $22-85 \%$ (median, 43\%) of patients and in 34-62\% (median, 36\%) of leads. ${ }^{12}$ No procedure-related deaths due to TLE using locking stylets were reported (Figure 1).

Important limitations to the use of a locking stylet exist. A broken conductor or distorted central lumen renders it impossible to introduce the stylet. Excessive force can dislocate the stylet, or the distal conductor coil can still unwind or even disconnect from the electrode.

\section{Mechanical dilator sheaths}

A common third step in the stepwise approach of lead extraction is the use of a mechanical dilator sheath. A telescoping sheath, available in different materials (i.e., polypropylene,
Teflon $^{\circledR}$, or stainless steel), is advanced along the lead to disrupt and dilate the encapsulating fibrotic attachments. A locking stylet is still required to enable countertraction as the sheath is advanced. On reaching the distal electrode, the larger bore outer sheath is positioned and held against the myocardium to prevent its inversion during traction on the locking stylet. The force is, therefore, applied at the adherent scar without gross displacement of the myocardium (Figure 2B).

Cecchin et al. ${ }^{14}$ reported that after a mean lead dwell time of 7 years, $20 \%$ of the leads were successfully extracted using dilator sheaths, resulting in an overall success of $54 \%$ after simple traction, locking stylet, and mechanical sheath use. Results using conventional sheaths also include the use of a femoral approach, and are reported in the U.S. Lead Extraction Database. ${ }^{15}$ Of the 2,195 leads, $86.8 \%$ were completely removed, whereas $7.5 \%$ were partially removed. Although countertraction prevents invagination of the myocardium, perforation of the myocardium is still possible. The lead tip may become incorporated into the 

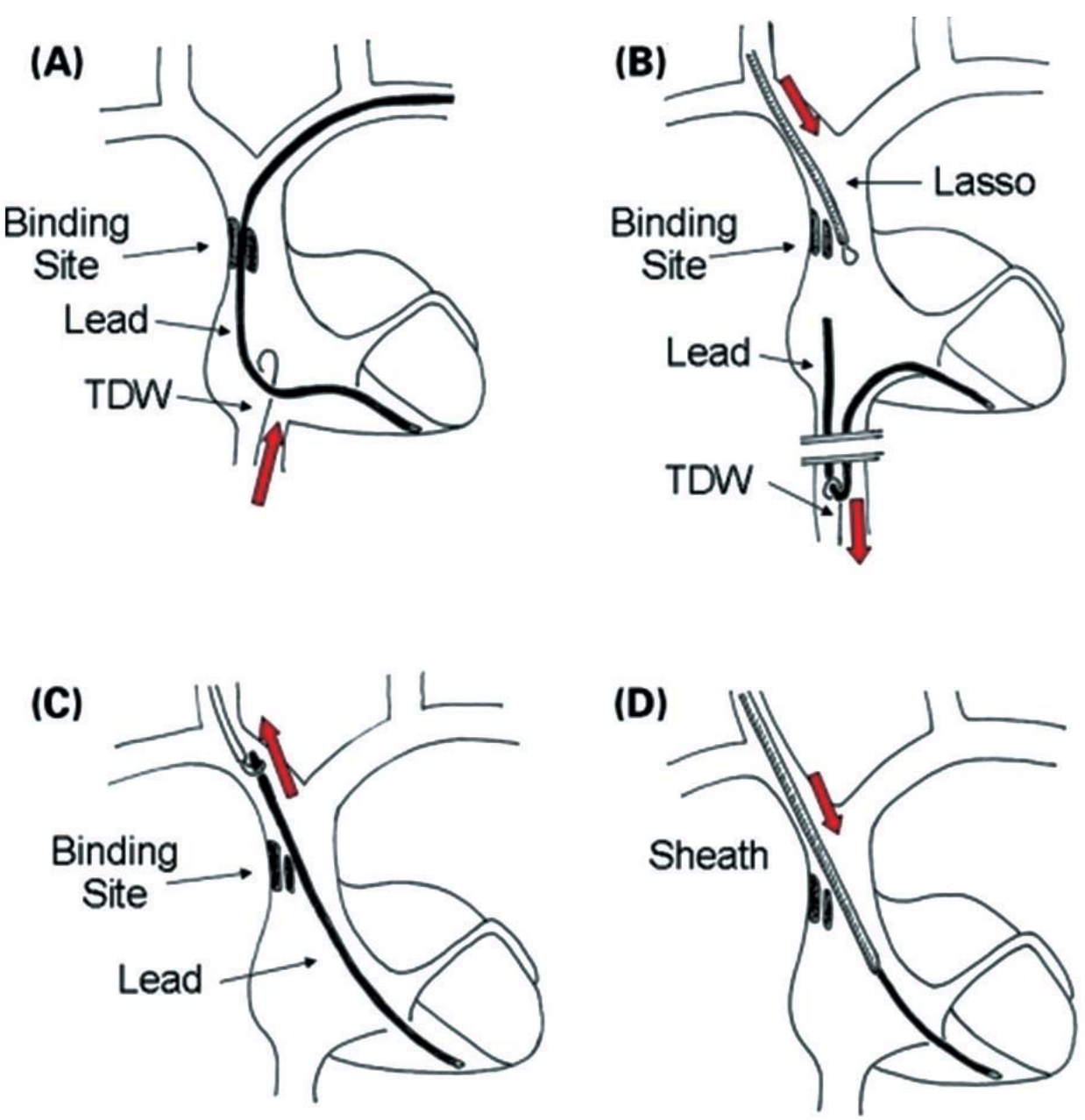

Figure 3. Consecutive steps of the internal transjugular approach (ITA) in case of crossover from the venous entry approach (VEA). (A) A tip deflecting wire is advanced via the femoral vein in order to assess the possibility to grasp the lead and to move it. (B) Once the lead has been grasped, it is pulled down in the inferior vena cava and slipped through the binding site; a Lasso, introduced through the internal jugular vein, is advanced near the proximal end of the lead. (C) The lead is caught by the Lasso, pulled up and exposed through the jugular vein. (D) Dilatation using a dilating sheath is performed. See the text for further details.

TDW, tip deflecting wire.

myocardium, leading to perforation after dislocation of the tip. Moreover, the possibility of increasing the force using countertraction can lacerate the myocardium, especially in the thin-walled atrium. ${ }^{16}$

\section{Femoral and transjugular extraction techniques}

A transfemoral approach is helpful when access or extraction via the implanting vein is impossible or when the leads are fractured or cut. The Needle's Eye Snare is the most frequently used tool for lead extractions via the transfemoral approach. Usually, the use of femoral snare is the last step in TLE (Figure 2D). Bracke et al. ${ }^{17}$ reported the results of the transfemoral approach in a large cohort of patients, and the mean dwell time of the leads was 7.6 years. After simple traction had failed, $98 \%$ of the remaining leads were successfully extracted using the Needle's Eye Snare. No procedurerelated deaths were observed, major complications were observed in $0.6 \%$ of the patients (two patients with cardiac avulsion requiring surgical intervention), and no minor complications occurred.

The transjugular approach enables the removal of previously cut leads that have retracted into the central venous circulation 

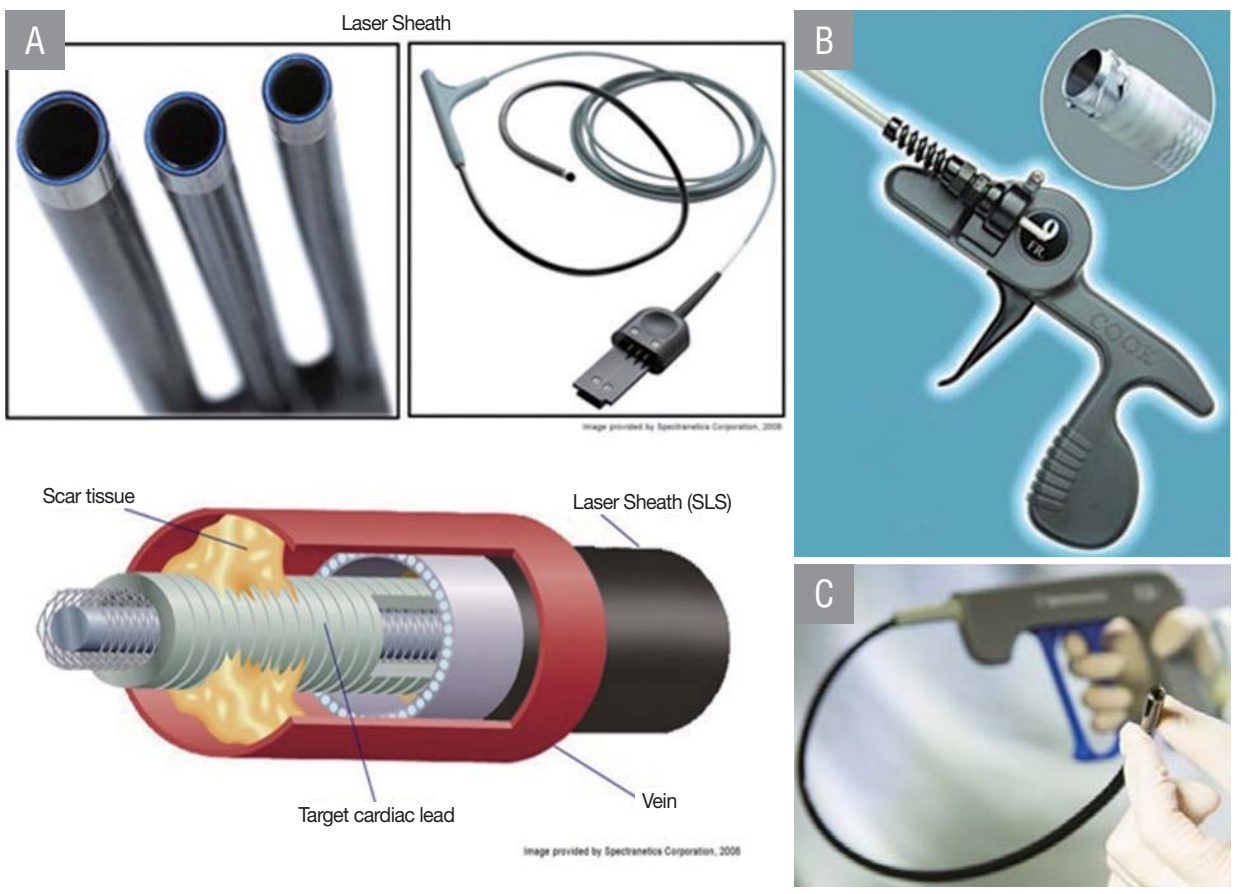

Figure 4. Powered traction tools. A, laser sheath. B, Cook evolution lead extraction sheath. C, Spectranetics' TightRail ${ }^{\circledR}$ rotating dilator sheath

and/or have been damaged during an extraction performed via a superior approach. In a large single-center study by Bongiorni et al., ${ }^{18}$ the TLE approach using simple traction, dilator sheaths, and/or a femoral snare was successful in $89 \%$ of the leads. However, extraction of the remaining leads was attempted via a transjugular approach, resulting in a total success rate of $99 \%$. Consecutive steps of the internal transjugular approach are presented in Figure 3..$^{18}$

\section{Powered traction tools}

Non-po wered sheaths use blunt dissection, while powered extraction sheaths use an energy source to disrupt adhesions between the lead and the endothelial or endocardial wall. Powered sheaths include laser sheaths, electrosurgical dissection sheaths, and rotating threaded tip sheaths. Powered traction tools are usually applied during simple traction, while non-powered traction tools fail in a stepwise approach.

\section{Laser sheaths}

A laser sheath is a tubular structure that passes over the PM lead. It consists of a thin layer of optical fibers sandwiched between polymer walls. The distal tip delivers a ring of laser light in pulses to a tissue depth of $100 \mu \mathrm{m}$, so that only the tissue immediately in contact with the sheath tip dissolves. Thus, the fibrous tissue encapsulating the lead body is removed in a controlled manner, and occluded vasculature can be re-canalized (Figure 4A). Studies in which patients underwent laser sheath extraction demonstrated clinical success after stepwise approach in 85-96\% (median, 94\%) of patients and 93-100\% (mean, 95\%) of leads (lead age range, 1.1-6.0 years). Procedure-related mortality was observed in $0-2.7 \%$ of the patients, with major and minor complications in $0-7.3 \%$ and $0-8.0 \%$ of the patients, respectively (Figure 1).12

\section{Electrosurgical dissection sheath}

The electrosurgical dissection sheath utilizes radiofrequency energy, similar to the cautery tool used in surgery, to cut through fibrous tissue. Two electrodes are exposed at the tip of the sheath, which allows linear dissection of adhesions comparable to a cautery tool. As opposed to the laser sheath, the electrosurgical dissection sheath permits localized application of energy instead 
of circumferential dissection.

\section{Rotating threaded tip sheaths}

The most recent addition to the equipment for the lead extractionist is a "hand-powered" rotating threaded tip sheath. This sheath is attached to a handle that controls the rotation of a threaded screw mechanism at the tip of the sheath, causing it to bore through adhesions around the lead. The Evolution ${ }^{\circledR}$ and Spectranetics TightRail ${ }^{\circledR}$ rotating dilator sheaths are currently the only rotating threaded tip sheaths available, and they have been advocated as especially advantageous in disrupting calcified fibrosis (Figure 4B and 4C). ${ }^{19}$ The Evolution tool showed an overall success rate of $88 \%$, with an average lead age of 7.1 years. Major complications occurred in $0.7-1.5 \%$ of the patients, with vascular tear requiring surgery. ${ }^{20,21}$

\section{Extraction of ICD and coronary sinus leads}

The literature evidence supporting safe and successful extraction of standard pacemaker leads is extensive. ${ }^{10,22}$ However, the use of nonstandard leads such as ICD or coronary sinus (CS) leads can pose some challenges, although the same tools and techniques may be used.

\section{ICD leads}

The shock coils of high-voltage ICD leads allow fibrous ingrowth, resulting in dense vascular and myocardial adhesions. ${ }^{23}$ Therefore, compared with regular PM leads, ICD leads might pose an additional challenge and could have an increased risk of complications. Chronically implanted dual-coil ICD leads can pose the greatest challenge to extraction because the proximal externalized coil attracts additional adhesions at the level of the

Table 2. Definition and classification of complications

\section{Major complications}

1. Death

2. Cardiac avulsion or tear requiring thoracotomy, pericardiocentesis, chest tube, or surgical repair

3. Vascular avulsion or tear (requiring thoracotomy, pericardiocentesis, chest tube, or surgical repair)

4. Pulmonary embolism requiring surgical intervention

5. Respiratory arrest or anaesthesia related complication leading to prolongation of hospitalization

6. Stroke

7. Pacing system related infection of a previously non-infected site

\section{Minor complications}

1. Pericardial effusion not requiring pericardiocentesis or surgical intervention

2. Hemothorax not requiring a chest tube

3. Hematoma at the surgical site requiring reoperation for drainage

4. Arm swelling or thrombosis of implant veins resulting in medical intervention

5. Vascular repair near the implant site or venous entry site

6. Hemodynamically significant air embolism

7. Migrated lead fragment without sequelae

8. Blood transfusion related to blood loss during surgery

9. Pneumothorax requiring a chest tube

10. Pulmonary embolism not requiring surgical intervention 
superior vena cava, which further augments the risk of venous tear during extraction. This makes the use of single-coil leads at implant an attractive option, particularly in younger patients who are more likely to require revisions during their lifetime. In experienced hands, ICD lead extractions have been reported to have an overall success rate of $88-100 \%$ (median, 99\%) of leads or 98-100\% (median, 96\%) of patients.

\section{Coronary sinus lead extraction}

Limited experience regarding CS lead extraction has been reported, but initial reports ${ }^{24,25}$ suggest that the vast majority of these leads can be safely removed. Simple traction of the lead is often successful; however, concerns exist regarding the perforation of the tortuous and fragile CS and complications in the often frail CRT recipients.

\section{Complications of lead extraction}

Most complications can be defined and/or classified according to the level of their severity (Table 2). Complication rates among various intravascular extraction techniques are comparable. All techniques (except direct traction) rely on countertraction; hence, tamponade resulting from perforation after dislocation of the lead tip is common to all these techniques. Analysis of data from a registry of 5,339 lead extractions over 10 years revealed a major complication rate of $1.6 \% .{ }^{16}$ The predictors of risk for complications include the experience of the treating physician, requirement of a large number of leads for extraction, long implant duration of the oldest lead, ICD lead removal, and use of laser.

Facilities, training and equipment required for safe lead extraction

Lead extraction procedures should ideally be performed in hospitals with onsite facilities for cardiothoracic surgery. The surgical team must be readily available with the necessary equipment and facilities for rapid thoracotomy and sternotomy.

Given the technical challenges and risk of life-threatening complications, clinicians who wish to perform this procedure should be adequately trained in extraction techniques and management of complications. They should seek training only in hospitals that have sufficient procedural volume of device implantations and extractions to maintain the skills of the physician and the team.

\section{Conclusion}

Transvenous lead extraction includes invasive techniques primarily designed to address concerns related to cardiac pacemaker and ICD lead management. The number of lead extractions continues to rise, and is likely to increase further in the foreseeable future, with the ever-increasing CRM implants and extraction indications. No single technique is sufficient to address all extractions, and centers performing extractions should have the necessary expertise and equipment to perform different techniques depending on the clinical scenario. A stepwise extraction approach can result in a clinically successful TLE in up to $100 \%$ of the leads, with a relatively low risk of procedure-related mortality and complications. In case of a lack of a local physician and institutional expertise, the patient should be referred to a center with appropriate facilities. The future of lead extraction would benefit from recommendations regarding extraction approaches and the timing of crossover to a different extraction method to further improve success rates and prevent unnecessary complications.

\section{References}

1) Brignole M, Auricchio A, Baron-Esquivias G, Bordachar P, Boriani G, Breithardt OA, Cleland J, Deharo JC, Delgado V, Elliott PM, Gorenek B, Israel CW, Leclercq C, Linde C, Mont L, Padeletti L, Sutton R, Vardas PE; ESC Committee for Practice Guidelines (CPG), Zamorano JL, Achenbach S, Baumgartner H, Bax JJ, Bueno H, Dean V, Deaton C, Erol C, Fagard R, Ferrari R, Hasdai D, Hoes AW, Kirchhof P, Knuuti J, Kolh P, Lancellotti P, Linhart A, Nihoyannopoulos P, Piepoli MF, Ponikowski P, Sirnes PA, Tamargo JL, Tendera M, Torbicki A, Wijns W, Windecker S; Document Reviewers, Kirchhof P, Blomstrom-Lundqvist C, Badano LP, Aliyev F, Bänsch D, Baumgartner H, Bsata W, Buser P, Charron P, Daubert JC, Dobreanu D, Faerestrand S, Hasdai D, Hoes AW, Le Heuzey JY, Mavrakis H, McDonagh T, Merino JL, Nawar MM, Nielsen JC, Pieske B, Poposka L, Ruschitzka F, Tendera M, Van Gelder IC, Wilson CM. 2013 ESC Guidelines on cardiac pacing and cardiac 
resynchronization therapy: the Task Force on cardiac pacing and resynchronization therapy of the European Society of Cardiology (ESC). Developed in collaboration with the European Heart Rhythm Association (EHRA). Eur Heart J. 2013;34:2281-2329.

2) Epstein AE, DiMarco JP, Ellenbogen KA, Estes NA 3rd, Freedman RA, Gettes LS, Gillinov AM, Gregoratos G, Hammill SC, Hayes DL, Hlatky MA, Newby LK, Page RL, Schoenfeld MH, Silka MJ, Stevenson LW, Sweeney MO; American College of Cardiology Foundation; American Heart Association Task Force on Practice Guidelines; Heart Rhythm Society. 2012 ACCF/AHA/HRS focused update incorporated into the ACCF/AHA/HRS 2008 guidelines for device-based therapy of cardiac rhythm abnormalities: a report of the American College of Cardiology Foundation/ American Heart Association Task Force on Practice Guidelines and the Heart Rhythm Society. Circulation. 2013;127:e283-352.

3) John Camm A, Nisam S. European utilization of the implantable defibrillator: has 10 years changed the 'enigma'? Europace. 2010;12:1063-1069.

4) Epstein AE, DiMarco JP, Ellenbogen KA, Estes NA 3rd, Freedman RA, Gettes LS, Gillinov AM, Gregoratos G, Hammill SC, Hayes DL, Hlatky MA, Newby LK, Page RL, Schoenfeld MH, Silka MJ, Stevenson LW, Sweeney MO, Tracy CM, Epstein AE, Darbar D, DiMarco JP, Dunbar SB, Estes NA 3rd, Ferguson TB Jr, Hammill SC, Karasik PE, Link MS, Marine JE, Schoenfeld MH, Shanker AJ, Silka MJ, Stevenson LW, Stevenson WG, Varosy PD; American College of Cardiology Foundation; American Heart Association Task Force on Practice Guidelines; Heart Rhythm Society. 2012 ACCF/AHA/HRS focused update incorporated into the ACCF/ AHA/HRS 2008 guidelines for device-based therapy of cardiac rhythm abnormalities: a report of the American College of Cardiology Foundation/American Heart Association Task Force on Practice Guidelines and the Heart Rhythm Society. J Am Coll Cardiol. 2013;61:e6-75.

5) Park JS, Pak HN, Lee MH, Kim SS, Joung B. Implantable cardioverter-defibrillator lead extraction by conventional traction and counter-traction technique. Korean Circ J. 2010;40:418-420.

6) Park JS, Pak HN, Lee MH, Kim SS, Joung B. Implantable cardioverter-defibrillator lead extraction by conventional traction and counter-traction technique. Korean Circ J. 2011;41:164-166.

7) Cho H, Kim M, Uhm JS, Pak HN, Lee MH, Joung B. Transvenous pacemaker lead removal in pacemaker lead endocarditis with large vegetations: a report of two cases. Korean Circ J. 2014;44:118-121.
8) Kim D, Baek YS, Lee M, Uhm JS, Pak HN, Lee MH, Joung B. Remnant pacemaker lead tips after lead extractions in pacemaker infections. Korean Circ J. 2016;46:569-573.

9) Becker AE, Becker MJ, Claudon DG, Edwards JE. Surface thrombosis and fibrous encapsulation of intravenous pacemaker catheter electrode. Circulation. 1972;46:409-412.

10) Smith MC, Love CJ. Extraction of transvenous pacing and ICD leads. Pacing Clin Electrophysiol. 2008;31:736-752.

11) Wilkoff BL, Love CJ, Byrd CL, Bongiorni MG, Carrillo RG, Crossley GH 3rd, Epstein LM, Friedman RA, Kennergren CE, Mitkowski P, Schaerf RH, Wazni OM; Heart Rhythm Society; American Heart Association. Transvenous lead extraction: Heart Rhythm Society expert consensus on facilities, training, indications, and patient management: this document was endorsed by the American Heart Association (AHA). Heart Rhythm. 2009;6:1085-1104.

12) Buiten MS, van der Heijden AC, Schalij MJ, van Erven L. How adequate are the current methods of lead extraction? A review of the efficiency and safety of transvenous lead extraction methods. Europace. 2015;17:689-700.

13) de Bie MK, Fouad DA, Borleffs CJ, van Rees JB, Thijssen J, Trines SA, Bootsma M, Schalij MJ, van Erven L. Trans-venous lead removal without the use of extraction sheaths, results of $>250$ removal procedures. Europace. 2012;14:112-116.

14) Cecchin F, Atallah J, Walsh EP, Triedman JK, Alexander ME, Berul CI. Lead extraction in pediatric and congenital heart disease patients. Circ Arrhythm Electrophysiol. 2010;3:437-444.

15) Smith HJ, Fearnot NE, Byrd CL, Wilkoff BL, Love CJ, Sellers TD. Five-years experience with intravascular lead extraction. U.S. Lead Extraction Database. Pacing Clin Electrophysiol 1994;17:2016-2020.

16) Byrd CL, Wilkoff BL, Love CJ, et al. Intravascular extraction of problematic or infected permanent pacemaker leads: 1994-1996. U.S. Extraction Database, MED Institute. Pacing Clin Electrophysiol. 1999;22:1348-1357.

17) Bracke FA, Dekker L, van Gelder BM. The Needle's Eye Snare as a primary tool for pacing lead extraction. Europace. 2013;15:10071012.

18) Bongiorni MG, Soldati E, Zucchelli G, Di Cori A, Segreti L, De Lucia R, Solarino G, Balbarini A, Marzilli M, Mariani M. Transvenous removal of pacing and implantable cardiac defibrillating leads using single sheath mechanical dilatation and 
multiple venous approaches: high success rate and safety in more than 2000 leads. Eur Heart J. 2008;29:2886-2893.

19) Maytin M, Epstein LM. The challenges of transvenous lead extraction. Heart. 2011;97:425-434

20) Mazzone P, Tsiachris D, Marzi A, Ciconte G, Paglino G, Sora N, Gulletta S, Vergara P, Della Bella P. Advanced techniques for chronic lead extraction: heading from the laser towards the evolution system. Europace. 2013;15:1771-1776.

21) Oto A, Aytemir K, Yorgun H, Canpolat U, Kaya EB, Kabakci G, Tokgozoglu L, Ozkutlu H. Percutaneous extraction of cardiac pacemaker and implantable cardioverter defibrillator leads with evolution mechanical dilator sheath: a single-centre experience. Europace. 2011;13:543-547.
22) Bongiorni MG, Soldati E, De Lucia R, Marzilli M. Techniques for transvenous leads extraction. Minerva Cardioangiol. 2007;55:771781.

23) Epstein LM, Love CJ, Wilkoff BL, et al. Superior vena cava defibrillator coils make transvenous lead extraction more challenging and riskier. J Am Coll Cardiol. 2013;61:987-989.

24) Kasravi B, Tobias S, Barnes MJ, Messenger JC. Coronary sinus lead extraction in the era of cardiac resynchronization therapy: single center experience. Pacing Clin Electrophysiol. 2005;28:51-53.

25) Tyers GF, Clark J, Wang Y, Mills P, Bashir J. Coronary sinus lead extraction. Pacing Clin Electrophysiol. 2003;26:524-526. 